\title{
Product Carbon Footprint of Wooden Products in Sri Lanka: Special Reference to a Life Cycle of an Arm Chair
}

\author{
L. Senadheera ${ }^{1 *}$, H. Ranasinghe ${ }^{1}$, H. Amarasekera ${ }^{1}$, S. Wahala ${ }^{2}$ \\ ${ }^{I}$ Department of Forestry and Environmental Science, University of Sri Jayewardenepura, Sri Lanka \\ ${ }^{2}$ University of Sabaragamuwa, Sri Lanka \\ *lakminisenadheera@gmail.com
}

\begin{abstract}
Forest and forest products have a vital role in mitigation of the global climate change. The main objective of this study was to assess the carbon emissions in the manufacturing of wood products taking an example of the production of an arm chair using life cycle assessment approach (LCA) which provides a methodological framework for evaluating environmental performance over the life cycle of a product, process, or an activity.

The product Carbon Footprint was assessed for a typical wooden arm chair manufactured in an average sawmill. Assessment boundary was cradle to grave. The system boundary encompasses each product manufacturing process including material (logs, wood, resin, fuels) transport to each production facility. Transportation distances were reported in surveys and used to calculate product transported per kilogram-kilometers $(\mathrm{kg}-\mathrm{km})$. The embedded C flux in harvested timber, GHG emissions and the flow of embedded $\mathrm{CO}_{2}$ stock during the processing were analysed. The cumulative system boundary includes all upstream flows of energy, fuel, and raw material for production. Energy consumed during transportation between the harvesting life-cycle stage and manufacturing accounts for actual distances reported from each production region.
\end{abstract}

The functional unit for the product was referenced to $1 \mathrm{~m}^{3}$ of the product. All input and output data within the cumulative system boundary were allocated to the functional unit of product and co-products in accordance with International Organisation for Standardisation.

The data represent average regional data from sample studies. Umberto for Carbon Software was used for the analysis. The total life cycle consists of 08 stages, raw material and timber harvesting, timber depot operations, log conversions, wood preservation, timber seasoning, manufacturing, use phase, end of use/ final disposal.

Based on the calculations, percentages of GHG emissions in each stage of life cycle were $54 \%$ for raw material and timber harvesting, $4 \%$ for timber depot operations, $11 \%$ for $\log$ conversions, $5 \%$ wood preservation, $1 \%$ for timber seasoning, $12 \%$ for manufacturing and $13 \%$ for use phase and end of use/final disposal. From the above results it is apparent that as carbon emissions are greatest at the timber harvesting stage, measures should be taken to introduce more efficient and effective machinery and methodologies to reduce the emissions.

Keywords: Product carbon footprint, Wood products, Life cycle analysis, Climate change 